\title{
Refugiados diante da nova ordem mundial*
}

\author{
Michel Agier \\ Tradução de Paulo Neves
}

U ma mão quefere, a outra quesocorre. Em outubro de2001, no Afeganistão, e depois em abril de 2003, no Iraque, os Estados U nidos forneceram 0 espetáculo, em todas as telas do planeta, de uma visão extremamente maniqueístae, no entanto, exata do queé hoje sua concepção de associação entre a guerra e o humanitário.

0 acontecimento global da intervenção americana no Afeganistão, apresentada como resposta aos atentados de 11 de setembro de 2001, mostrou a perfeita simultaneidade entre uma ofensiva guerreira que então se pretendia a mais rápida, circunscrita e eficaz possível, mas que na prática revelou-se longa e bem menos "limpa" que o que fora anunciado, e uma intervenção humanitária que deveria vir em auxílio às populações civis direta ou indiretamente atingidas pela ofensiva: víveres e medicamentos lançados sobre as zonas bombardeadas, mas também abertura, no Paquistão, de mais de 75 novos sítios do $A C N \cup R^{1}$ ao longo da fronteira, mobilização urgente de mil agentes do ACN UR, construção de dezenas de campos onde abrigar os refugiados afegãos, fornecimento de 80 mil tendas, milhares de cobertores etc. M as o Paquistão, que já acolhera mais de 2 milhões de exilados afegãos, fechou suas fronteiras, dando a entender que não poderia mais recebêlos atitude hoje cada vez mais adotada pelos países, seguindo o exemplo, na época, do Irã, outro país vizinho ao Afeganistão. Esses interesses opostos acabaram por tornar a situação ainda mais dramática, fazendo com que os

* Alguns trechos deste texto foraminicialmentepublicadossob o título "La main gauche de l'Empire" na revista M ultitudes, 11: 67-77, inverno 2003 (http:// multitudes.samizdat.net/ La-main-gauche-de-lEmpire.html).

1. Alto Comissariado das N ações U nidas para os Refugiados. 
civis oscilassem, de um lado e de outro da fronteira, entre os campos e a clandestinidade.

0 humanitário como mão esquerda do Império

Esses fatos mostraram, em resumo, os três elementos que constituem atualmente o humanitário como fator indispensável à edificação social e moral do "Império", esse mundo coligado como uma única sociedade de controle em escala planetária (cf. $\mathrm{H}$ ardt e $\mathrm{N}$ egri, 2000) e hoje dominado pelos "Falcões" do governo dos Estados U nidos. 0 primeiro desses elementos éa existência simultânea de um conjunto de guerras, de violências cole tivas, de distúrbios e terrores que conduzem as populações civis à morte ou à fuga: guerras mais ou menos rápidas, "eficazes" ou, ao contrário, morosas, intermináveis, sujas e de "fraca intensidade", elas nunca parecem unificadas, cada uma dependendo de um tratamento isolado, casuístico, da ordem da polícia que exclui a política. Além disso, essas guerras despolitizadas, e em geral sem enraizamento social, tomam freqüentemente a população civil como refém, como alvo voluntário, ou a atingem como efeito colateral inevitável da confusão crescente entre os locais de vida, especialmente urbanos, e os locais de guerra. 0 s exércitos regulares são assim levados hoje a rever as modalidades da guerra, aprendendo, em particular, a fazer guerra nas cidades, o que é um fenômeno em rápido crescimento: para os soldados, "o terreno urbano é mais complicado", observa Jean-Louis D ufour (2001, p. 37), as formas materiais e espaciais da cidade são bem menos previsíveis que as das florestas, das planícies ou dos mares, que constituem também espaços mais ou menos vazios de homens, ao contrário das cidades. Atualmente, $75 \%$ das vítimas de guerra são civis, ou até mais (na C olômbia, calcula-se $90 \%$ ).

O segundo componente do humanitário hoje é o conteúdo da própria intervenção, na medida em que esta acompanha de perto as guerras e as violências, e representa seu tratamento legítimo. Ao encarregar-se das vítimas, ela instaura ao mesmo tempo o controle e os cuidados: o princípio do care, cure and control aplica-se idealmente nos campos de refugiados, que são dispositivos policiais, alimentares e sanitários eficazes para o tratamento das massas vulneráveis. Se ali as vítimas são mantidas num mínimo de vida, isto é, segundo normas nutricionais de simples sobrevivência, elas também estão sob controle. A atenção constante dada pelos agentes do ACN UR ao registro eà identificação dos refugiados, os tráficos diversos que existem em 
torno da atribuição das carteiras (as do governo de acolhida, do ACN UR ou do PAM ${ }^{2}$ ), a vontade de muitos governos dos países de acolhida de agrupá-los em campos em vez de deixá-los disseminados no seio da população, todas essas práticas denotam uma mesma obsessão de controle. Sob esse aspecto, os campos representam uma das múltiplas ramificações da "sociedade de controle".

Enfim, o terceiro componente do dispositivo humanitário mundial é 0 isolamento: os sítios humanitários situam-se nas margens, afastados dos locais de vida comuns, nos limiares da vida social e da vida, simplesmente. Esses limiares têm uma forma: os centros de trânsito, os campos de detenção dos que pedem asilo (Woomera, na Austrália), os campos de agrupamento de deslocados (no Sudão, em Angola), os centros de acolhida de urgência (Sangatte, na França), as zonas de espera de pessoas em trânsito nos aeroportos (os Zapi 2 e 3 do Charles de G aulle, em Paris), certas zonas portuárias, certos barcos (o "Tampa"), minúsculas ilhas (N auru): todas essas formas, por diversas que sejam, compõem com os campos de refugiados um conjunto de espaços, hoje em crescimento, para manter refugiados, "clandestinos" e indesejáveis à espera, em sobrevivência e sem direitos. Encerrados no exterior, são espaços de exceção. 0 ol har dirigido a eles enraízase numa relação egocêntrica do tipo centro-periferia: ele só se interessa pelos detalhes da vida interna da periferia na medida em que esses detalhes põem em causa o próprio centro. Assim, o "escândalo" revelado em fevereiro de 2002 pelo ACN UR e pela organização não-governamental Save the $C$ hildren Found sobre a exploração sexual de refugiados menores de idade na África ocidental, em particular por agentes de diversas organizações humanitárias, simplesmente deixou de existir tão logo se pôde estabelecer 0 não-lugar na atitude dos brancos. N ossa moral estando salva, o funcionamento, as perversões e as corrupções dos sítios humanitários podem ser atribuídos a um regime de exceção no qual o arbitrário e seus atores agem livremente em sua própria ordem das coisas.

Com a constituição dos terrenos do humanitário como espaços de exceção, como não-lugares, a história política recente fez nascer uma categoria mundial de sem-lugar esem-direitos mais ampla que soma dos refugiados propriamente ditos. Aliás, o número de refugiados "estatutários" (isto é, definidos pela Convenção de $G$ enebra de 1951) diminui regularmente em favor dos deslocados internos (que abandonam sua local idade, mas permanecem no país por não poderem ser acol hidos no exterior) e dos refugiados cujos estatutos só dão direito a proteções temporárias: asilo territorial, hu-
2. Programa Alimentar Mundial das Nações U nidas, responsável pelas rações alimentares aos refugiados.

3.Ver Agier e Bouchet-Saulnier (2003). 
4. Ver Bouteillet-Paquet (2002) eo conjunto do dossiê "LesFrontières du droit d'asile", revista $\mathrm{H}$ ommes et $\mathrm{M}$ igrations, 1238, jul.-ago. 2002.

5.Ver, em particular, as duas últimas publicações do Alto Comissariado das $\mathrm{N}$ ações U nidas para os R efugiados (1997, 2000).

6. 0 srefugiadospalestinossão "administrados" por um organismo específico das $\mathrm{N}$ ações Unidas, o U N RWA.

7. "Internally Displaced Persons", segundo a definição da ONU, categoria de possuidores de direito que designa pessoas que deixaram sua região de origem por causa de violências ou de guerras internas, mas permaneceram no interior das fronteiras de seu país.

8. N o primeiro semestre de2006, segundo os anúncios do ACN UR, não haveriamaisque 10 milhões de refugiados. manitário e outros estatutos "subsidiários". Assim, na U nião Européia, em 1999, apenas um quarto dos refugiados eram "estatutários"4.

$\mathrm{N}$ a aurora do século XXI, cerca de 50 milhões de pessoas são qualificadas pelas N ações U nidas como "vítimas de deslocamentos forçados"5. Entre estas, de 13 a 18 milhões, segundo o ano, são refugiados stricto sensu, isto é, que vivem fora de seu país. M aciçamente concentrados na Ásia (mais de 6 milhões) e na África ( 7 a 8 milhões), esses refugiados somam-se aos 3 miIhões de palestinos refugiados desde os anos de 1940 e 1960 em diversos países do 0 riente Próximo (Líbano, Jordânia, Síria, território palestino) ${ }^{6}$. Por outro lado, um pouco mais de 3 milhões de pessoas são consideradas pelo ACN U R como returnees, ou "em via de repatriamento". Enfim, de 25 a 30 milhões, segundo as estimativas, são ID Ps? .

Todos esses números são aproximativos e contestáveis. Elesnão incluem um número vasto (mas difícil de calcular com precisão) de refugiados não declarados e considerados "clandestinos". São, por exemplo, os 130 mil refugiados afegãos ditos "invisíveis" após o ataque americano de outubronovembro de 2001, e que o AC N U R fez reconhecer in extremis como "refugiados" pelo governo paquistanês, para poder alojá-los nos campos que acabara de montar com urgência ao longo da fronteira afegã. São também uma parte dos refugiados somalis, etíopes ou ruandeses, ditos "auto-instalados" nos países limítrofes, uns porque preferem tentar a sorte na clandestinidade e na economia informal em vez de ficar encerrados em campos, outros, errantes, por não terem obtido reconhecimento oficial de seu estatuto de refugiado.

Se a diminuição, nosúltimos seis anos, do número oficial de refugiados stricto sensu ${ }^{8}$ corresponde a um aumento regular das outras categorias (ID PS, asilo territorial, asilo humanitário etc.), deve-se constatar uma mudança mais profunda. Ao longo das décadas, a imagem dominante do exílio transformou-se, adquiriu sucessivamente a aparência do refugiado, do deslocado interno e, agora, a do indeferido (closed file, na linguagem anglófona do ACN U R), ou seja, do clandestino. "R efugiado", "deslocado", "indeferido" representam assim três identidades categoriais históricas que a mesma pessoa pode também assumir, em alguns anos ou em alguns meses, em sua história de deslocamentos. As biografias percorrem essas identidades definidas segundo o princípio dos vasos comunicantes entre categorias e entre regiões do mundo.

A gestão dos indesejáveis estende-se e torna-se cada vez mais precisa no plano da produção das categorias dos espaços adequados. Ela mobiliza cada 
vez mais regularmente uma resposta combinada humanitária-policial, como se observa no tratamento dos africanos ditos "subsaarianos" no M arrocos, onde numerosas $0 \mathrm{~N} G \mathrm{~s}$ responderam aos apel os dos governos europeus e marroquino para se encarregar da retenção dos clandestinos. Com isso, a ação humanitária vê-se mais e mais "amarrada", e suas soluções de proteção acham-se incluídas nas políticas de controle. Por exemplo, o conceito de "asilo interno", introduzido nos últimos anos nas discussões entre os governos europeus, no quadro das estratégias de externalização do procedimento de asilo, parece ser um eco perfeito da experiência dos campos de deslocados internos nos países do sul, dirigidos ou criados por 0 N G sinternacionais. Ele representa, na política intergovernamental européia, o ideal deum duplo distanciamento: isolamento em campos e distanciamento nos países africanos. A estratégia, que visa a privilegiar países "tampões", especialmente na África do N orte, para isolar efiltrar os "estrangeiros", apóia-se no mesmo princípio de afastamento-encerramento dosindesejáveis 9 .

Certa perenidade caracteriza os sítios humanitários, apesar do aspecto provisório e do tratamento de urgência de cada situação observada. Aliás, pode-se pensar que esse aspecto provisório einacabado da gestão da vida na urgência, assim como o tratamento sistemático pelo humanitário dos estragos humanos das políticas guerrei ras ou excludentes e a colocação sob controle das populações indesejáveis, tem um caráter experimental para o conjunto da sociedade. As técnicas detratamento ede controle aplicadas nesses espaços de exceção podem ser transferidas e servir para administrar todo tipo de "restos" do sistema econômico e social mundial ${ }^{10}$.

Voltemos agora ao acontecimento evocado anteriormente. Em 2001, enquanto uma mão soltava sobre o Afeganistão víveres e medicamentos da O N U ou das 0 rganizações N ão-G overnamentais, a outra despejava bombas americanas, mostrando o espetáculo da mão esquerda do Império ${ }^{11}$. As enfermeiras de boa vontade prestam os primeiros socorros nas casas destruídas, os operadores de logística abrem com urgência pistas, cavam poços e constroem clínicas no meio do mato, os professores alfabetizam os filhos de refugiados em escolas de palha: são os homólogos mundiais e atuais, digamos pós-modernos, dos trabal hadores sociais posicionados à esquerda de um Estado que perde sua função de protetor do bem-estar social. Q uando a mão direita éformada pel os gerentes e pelos princípios de gestão da economia de mercado (livre empresa, competitividade, flexibilidade, retorno do investimento etc.), e provoca a ampliação e o aprofundamento da miséria social e moral, a "mão esquerda" tem uma dificuldade cada vez
9. Sobre essas questões, remeto adiversaspublicaçõesrecentes: o dossiê “L'Europe des camps. La mise à l'écart des étrangers" (ed. Jêrome Valluy), Cultureet conflits, 57, 2005; o dossiê "M igrations en Europe: lesfrontières delaliberté", M ultitudes, 19, 2005; e ainda "Carte des camps d'étrangers en Europe et dans les pays méditerranéens", deM igreurop (regularmentepublicadano site http://www.migreurop .org).

10. Para uma análise da extensão dosterrenosdo humanitário a todos os sem-direitos e sem-lugar, ver Agier (2002a).

11 A experiência prosseguiu, embora com resultados contestados, na intervenção angloamericana no Iraque em abril de 2003 (cf. Brauman e Salignon, 2003). 
maior de combater essa miséria, como Pierre Bourdieu (1993) bem assinalou. Por compaixão ou compensação, os trabal hadores sociais do Império buscam reparar, corrigir, reduzir os danos das guerras e das violências multiformes, intervir em última instância, isto é, exatamente para salvar vidas, habilitar novamente os corpos eajudar na ressocialização das vítimas. M ovidos por um espírito militante, penalizado pela baixa remuneração dos voluntários, engajados em "carreiras" pessoais marcadas pelo pacifismo, pelo humanismo, pelo esquerdismo ou pela religião, eles lutam contra todas as encarnações da mão direita, a mano dura, ao mesmo tempo que se vêem obrigados a compor com ela. A tensão caracteriza o laço apertado que une a política excludente e guerreira da ordem mundial unificada e sua mão esquerda humanitária.

Os clandestinos ou o direito à vida na ilegalidade

N o cotidiano, portanto, os trabalhadores do humanitário tratam a vida nua das vítimas absolutas, despojada detoda socialidade. 0 que eles conhecem, em princípio, são apenas as vítimas. No entanto, declarações e iniciativas, abertas ou escondidas, em resposta ao acantonamento, desenvolvemse no contexto humanitário, ena maioria das vezes revertendo o estatuto de vulnerabilidade que as organizações humanitárias, da O N U ou governamentais atribuem a seus beneficiários. A ação nasce na clandestinidade ou no quadro dos próprios campos. $D$ aremos alguns exemplos tomados em cada um desses dois contextos.

\section{Bogotá}

Em dezembro de 1999, cerca de duzentos desplazados colombianos(deslocados pela guerra no interior do país) ocupam a sede do CICR (Comitê Internacional da C ruz Vermelha), apoiando-se na proteção diplomática do lugar para melhor fazerem ouvir sua voz fora do país e não serem expulsos.

12. Certificado de deslocado que dá direito à ajuda mínima de alimento, saúde e al ojamento duranteseismeses.
Em breveserão mais demil a pedir o acesso à certificación ${ }^{12}$ ea reclamar uma ajuda financeira para "projetos produtivos" no local, três quartas partes dos ocupantes pedindo para não retornarem a suas casas e poderem se instalar em Bogotá. A polícia respondecercando ebarrando o acesso à rua do prédio. Enquanto o movimento obtém resultados parciais ao cabo de vários meses deluta, al guns desplazados decidem permanecer eocupar o imóvel, abandonado pelosempregadosdo CICR: no final de2002, 26 famílias viviam ainda 
no local ea administração colombiana não tem os meios legais de desalojáIos, já que se trata de um terreno "neutro" protegido. D esde 1997, ano em que foi votada uma lei parlamentar que reconhece o estatuto de desplazado como problema humanitário, numerosas invasões e ocupações de instituições ocorreram na Colômbia: ministérios, prefeituras, mastambém igrejas, embaixadas e sedes de organizações internacionais.

Q uando buscam ser um pouco menos vítimas passivas, os refugiados e deslocados atraem contra si novas suspeitas, que se acrescentam ao simples fato de provirem de uma região dominada pela guerra "suja". Assim, os desplazados que invadiram a sede do CICR foram "investigados" pela imprensa e pelos serviços policiais, suspeitos de não serem todos "verdadeiros" desplazados. A poiando-se numa reportagem, um hebdomadário nacional conservador afirmou ser outra a trajetória de uma mulher deslocada em luta, suspeita demanter um bar para prostitutas num bairro da periferia, de ser mãe solteira de quatro filhos e de apresentar problemas psicológicos! (0 que não impede, a rigor, ter sido também deslocada pela guerra que devastou sua al deia de origem.) E concluía, ameaçador: "M uitos se fazem passar por deslocados e prejudicam a imagem dos que o são real mente... os justos pagam pelos pecadores".

\section{Luanda (Angola)}

No início de novembro de 2002, cerca de cinqüenta "representantes de refugiados" dediferentes países (Ruanda, Sudão, Congo-Brazzavillee RD C [República D emocrática do C ongo]) manifestaram-seno parlamento angolano para pedir condições de vida decentes. Esses refugiados ocupavam os escritórios do ACN UR, no centro da mesma cidade, desdeagosto de 2002, para protestar contra o mau tratamento que recebiam. Retirados do parlamento pela polícia, eles marcharam pelas ruas de Luanda e enviaram uma carta à AFP [France Presse], acusando o ACN U R de não Ihes fornecer 0 mínimo - água potável eabrigo. Pediam também para não ser repatriadose reclamavam a aplicação da Convenção de $G$ enebra para obter a fixação em outro país africano.

D o ponto de vista desses atores - que são, como ouvimos freqüentemente na Colômbia, pessoas "normais" colocadas em situações "anormais" -, tais ações não são senão o exercício de um direito à vida na ilegal idade. Esse direito aparentemente incongruente tem sua origem no abandono institucional dos indivíduos deslocados em seu próprio paíse, mais ainda, em ou- 
tros países. 0 quecria esseabandono? 0 que se perdecom ele? E, por exemplo, a que Estado de direito - e de direitos - pertence uma criança nascida num campo de refugiados?

0 paradoxo da "segunda geração" de refugiados mostra a atualidade da questão do lugar de exercício da cidadania. Como se localiza a geração dos que nasceram nos campos de refugiados ou que neles chegaram quando crianças, como no caso dos refugiados angolanos, somalis, burundienses ou palestinos? Falar de "segunda geração" de refugiados éum contra-senso do ponto de vista sociológico, pois se trata da emergência de gerações situadas no exílio de seus ascendentes. $\mathrm{M}$ as o termo corresponde bem ao estatuto (ou ao não-estatuto) dos filhos de refugiados, que, embora socializados num novo ambiente, permanecem ligados ao (não-)estatuto de seus pais refugiados. Um filho de refugiado angolano na Zâmbia não é nem zambiano, nem migrante angolano, não possui carteira de trabalho nem de residência, e não pode ser naturalizado: é apenas filho de refugiado angolano.

N um quadro jurídico não regulamentado, em quea definição do estatuto de pelo menos 50 milhões de indesejáveis é entregue à apreciação caso a caso, isto é, às vicissitudes de seu lugar de registro, a referência à localidade de origem resume e condensa todas as retóricas identitárias fundadas na origem, eas rejeições que daí decorrem. Ela se harmoniza com as classificações fundadas, por exemplo, na aparência ou no nome, como outras tantas metonímias deuma "raça" mal velada, eque remetea uma origem identitária fixa e definitiva. Racismo sem raça: nesse quadro contemporâneo, o retorno dos refugiados "a suas casas" aparece como a única solução para sua reinserção "normal" na ordem regular das coisas. 0 ACN UR dá firmemente "prioridade ao retorno", e as políticas de segurança européias vêem no reenvio das populações refugiadas "para suas casas" a justificação conservadora de seu próprio fechamento nacional.

Segundo Arjun Appadurai (1996), os refugiados seriam, ao contrário, os emblemas ou mesmo os principais atores deuma ordem pós-nacional emergente. No entanto, uma grande parte deles, particularmente na África e na Ásia, faz do momento do exílio - sempre associado, convém lembrar, a um conjunto de perdas materiais, familiares, econômicas - sua primeira experiência da importância dos Estados nacionais, quando devem fugir de um para se confrontar à ausência de direitos no outro, ou mesmo ao rechaço nas fronteiras, mais freqüente nos últimos anos do que antes. 0 Estado nunca esteve tão presente na vida desses refugiados. 
PasdanslePas de-Calais[N o Pas-de-C alais, não], disseo governador desse departamento francês, em outubro de 2002. Após a interdição de novos ingressos no centro de acolhida da C ruz Vermelha de Sangatte, no norte da França, 0 afluxo de refugiados na região e na cidade de Calais não se interrompeu. A estratégia desegurança, queconsideratodo refugiado um caso de polícia, retira deste toda esperança de cidadania e o instala num estigma identitário reforçado por cada ato policial de rejeição. Por acaso esse alto funcionário do Pas-de-Calais que quis fechar seu departamento sabia que estava parafraseando a fórmula $\mathrm{N}$ ot in my back yard [N o meu jardim, não], da qual foi tirada a sigla N I M BY para designar os bai rros privatizad os e fechados das classes médias brancas de LosAngeles (cf. D avis, 1997)?Eleparafraseava também declarações feitas por um representante do governo australiano em setembro de2001, em meio ao caso do "Tampa". N o final deagosto desseano, o cargueiro soviético “Tampa” recolheu pouco mais dequatrocentos refugiados afegãos no oceano índico, perto da ilha australiana de Christmas. Com a intenção de impedir a entrada em suas águas territoriais, o governo australiano enfrentou uma greve de fome dos refugiados, o que pôs o navio sob a vigilância de comandos de elite e mobilizou suas Forças Especiais Aéreas para impedir que ele acostasse em seu território nacional. No plano legal, isso contraria o princípio de "não-rechaço" inscrito na Convenção de Genebra de 1951 (um imigranteilegal não podeser rechaçado de volta a seu país de origem antes que seu pedido de asilo tenha sido examinado), o queobrigou o governo australiano a rever sua posição efez com queos refugiados suspendessem sua greve de fome. Eles foram transferidos para territórios próximos, na N ova Zelândia e na minúscula ilha de N auru, no Pacífico, um Estado independentede 11 mil habitantes estreitamenteligado à Austrália. No curso das disputas do governo australiano com a justiça ea O N U , um alto funcionário do M inistério daJ ustiça declarou publicamente: os refugiados clandestinos do Tampa "são livres para ir onde quiserem em terras fora da Austrália"13.

\section{Woomera (Austrália)}

O utros afegãos e iraquianos, refugiados na Austrália à espera de resposta a seu pedido de asilo, são mantidos durante meses em seis campos de detenção, entre eles o deW oomera, construído em 1999 na grandezona desértica
13 Citado em LeM onde, 4 de setembro de 2001. 
14.Ver Rivière(2002). ao campo militar ${ }^{14}$.

As soluções de sobrevivência clandestina de uma parte dos refugiados e dos deslocados internos só são clandestinas, portanto, na medida em que a ilegalidade Ihes é atribuída como condição de partida, e segundo a arbitrariedade do regime de exceção que governa os espaços de urgência e de intervenção humanitária. Esse abandono institucional faz com que os apelos à legalidadeeà moral (contra o uso de fal sos documentos, contra a corrupção de policiais e funcionários nacionais etc.) se tornem igualmente cínicos e ineficazes. $M$ ais ainda, o estigma que os apel os à moral alimentam justifica a transferência da resposta a esses problemas para uma intervenção humanitária durável eampliada, potencialmentemilitar-humanitária, como mostram o modelo australiano ou ainda o crescimento atual dos campos e centros de trânsito para os que pedem asilo nas fronteiras da Europa. O u seja, fora do mundo da palavra livre e da livre iniciativa política, fora de toda cidadania.

Os refugiados: ações e identificações nos campos

A precariedade das condições de vida e de habitat, a interdição oficial de trabalhar, de deslocar-se no país fora da zona dos campos, assim como, muitas vezes, a ausência de título oficial de refugiado na regulamentação do Estado de acolhida, têm por conseqüência que a vida dos próprios refugiados, mesmo quea priori não sejam clandestinos, geralmente só possa construir-se na alternativa entre a dependência da assistência humanitária e a iniciativa "clandestina": trabal ho informal, corrupção dos policiais que vigiam os deslocamentos etc.

$M$ as outros tipos de ação se desenvolvem dentro dos campos de refugiados. O s que já usufruem de al guma forma de reconhecimento pelas agências humanitárias adotam as $\mathrm{N}$ G s e as organizações internacionais como seus "parceiros sociais" naturais. Apesar das proibições ou das limitações que as autoridades dos campos impõem à existência de uma vida ativa profissional, associativa ou política - , alguns refugiados organizam manifestações de rua para a obtenção de melhores condições de vida, boicotes da 
ração alimentar do Programa Alimentar M undial (PAM ) ou greves de refugiados que trabalham como "voluntários comunitários" para as O NGs. Examinaremos alguns exemplos.

\section{Campos de Albadaria (Guiné Florestal)}

U ma manifestação de mulheres refugiadas de Serra Leoa ocorreu em agosto de 2003 num dos três campos de Albadaria (33 mil refugiados ao todo), o de Boreah, na Guiné Florestal. Cerca de cinqüenta manifestantes reuniram-se na via principal do campo e, no fim da tarde, impediram a passagem de veículos de $0 \mathrm{~N}$ Gs que se dirigiam à saída. É a estação das chuvas; tempestades violentas e abundantes duram com freqüência a noite toda. No campo de Boreah, que agrupa 7.500 refugiados, as paredes das habitações são de barro amassado com pal ha e tel hados de colmo, por onde a água rapidamente penetra, molhando chão, esteiras, cobertores e roupas. No período mais intenso das chuvas, em julho, o telhado e as paredes de terra de uma casa desmoronaram quando uma criança dormia no interior. 0 utros abrigos sofrem a mesma sorte. Enquanto isso, o ACN U R distribuia toldos plastificados a refugiados recém-chegados, deixando os mais antigos, presentes no campo há dois anos e meio, sem proteção. U m grupo de muIheres, separadas ou viúvas, refugiadas há mais tempo e vivendo com seus filhos, formou-se para pedir toldos ao ACN UR, alegando sua "vulnerabilidade" e referindo-se, para isso, às categorias de "mulheres sozinhas" e "progenitor sozinho".

D iante da recusa do ACN UR de satisfazer esse pedido, as mulheres viúvas e separadas fizeram uma manifestação sob chuva, acompanhadas dos fiIhos, e detiveram os veículos das $0 \mathrm{~N} G$ s que passavam naquelemomento na via principal do campo. 0 número delas aumentou, etambém certo nervosismo. Elas gritavam: "Q ueremos toldos!". O cupantes do carro de uma O N G foram tirados do veículo "para que visem o que era ficar debaixo da chuva", contou maistardealíder do movimento. 0 srefugiadospediam-lhes quese comprometessem por escrito a providenciar ostoldos. Diantedo protesto dos agentes humanitários, que explicaram que essa questão não era de suaal çada eque eles queriam apenas prosseguir com seu próprio trabal ho de assistência, as mulheres tiveram uma resposta radical: "Tomamos vocês todos por trabalhadores de O N Gs [ou seja: por semelhantes], assim como vocês nos tomam todos por refugiados". Elas opunham, assim, à compaixão dispensada caso a caso, eque as frustrava do direito de reivindicar, a idéia de 
15. São des: "Progenitor sozinho"; " "M ulher sozinha"; "Criança não acompanhada"; "Criança separada"; "C riança chefedefamília"; "Criança perdida”; "Pessoa idosaencarregada demenores"; "Pessoa idosa sozinha"; "D oente mental"; "D eficientefísico"; "Amputado"; "D oentecrôniCo"; "Surdo elou mudo"; "Cego"; "Sobrevivente deviolência". um confronto entre dois mundos distintos: de um lado, o dos "U.N." (representantes, em geral brancos, das organizações das $N$ ações U nidas e das O N Gs), de outro, o deseus beneficiários, os refugiados.

D epois as mulheres bloquearam um veículo da Cruz Vermelha e retiveram seus ocupantes no local até obter, após várias horas de discussão, uma resposta do governador e do representante local da administração guineana encarregada dos refugiados (o BCR, D epartamento de Coordenação dos Refugiados), que se comprometeram a receber uma del egação das manifestantes. Estas obtiveram seus toldos al guns dias após o encontro de quatro representantes com o governador.

É interessante reconsiderar esse acontecimento a partir do argumento de "vulnerabilidade" que as mulheres utilizaram para fazer val er seu direito. Esse argumento é tirado do próprio discurso humanitário. Por oposição à população circunvizinha, seja ela local ou mundial, a vulnerabilidade é o que distingue, de uma maneira geral, as vítimas das quais se ocupa o humanitário e o que legitima sua existência. Essa população ébem mais numerosa do que a das pessoas que sofrem de uma fragilidade física. Todos os refugiados em campo são, desse ponto de vista - digamos, do ponto de vista externo -, "vulneráveis". $\mathrm{N}$ a vida dos campos, porém, diferenciações internas são feitas permanentemente pelo ACN U R e pelas 0 N Gs de assistência humanitária para repartir a ajuda, e elas são vividas pelos refugiados alternadamente como vantagens a conquistar ou como exclusões a evitar. As categorias de vulnerabilidade oficialmente reconhecidas pelo ACN UR (quinze, ao todo) ${ }^{15}$ são definidas de acordo com um amplo leque que distingue as causalidades físicas das sociais. De uma maneira geral, o número de "vulneráveis" cresce na medida do deslocamento de sentido do físico para o social.

A vulnerabilidade contabilizada, e portanto reconhecida pelas organizações que administram os campos, caracteriza muito majoritariamente condições sociais ligadas ao estado de guerra eao êxodo. É o quese observa, por exemplo, nos números relativos aos "vulneráveis" do campo de Boreah, onde ocorreu a manifestação de mulheres que acabamos de mencionar. As categorias de população vulnerável são comuns ao conjunto das instalações do ACN UR no mundo, mas elas são representadas em maior ou menor grau em cada campo. No campo de Boreah, a totalidade dos considerados vulneráveis representa 1.140 pessoas (15\%). Elas se distribuem por ordem crescente, nas sete categorias de vulnerabilidade aplicadas nesse campo (ver Tabela a seguir). 


\begin{tabular}{ll}
\hline D oentes mentais & 12 \\
Crianças não acompanhadas & 51 \\
Crianças separadas & 83 \\
D eficientesfísicos & 92 \\
Pessoasidosas sozinhas & 104 \\
M ulheres sozinhas & 115 \\
Progenitores sozinhos & 683 \\
TotAL & 1.140 \\
\hline
\end{tabular}

Fonte: D ados ACN U R, campo de Boreah, Albadaria, GuinéFlorestal, outubro de 2003.

O s deficientes físicos representam $8 \%$ do conjunto. Se deixarmos de lado a categoria dos "doentes mentais", muito heterogênea (1\%), vê-se que a vulnerabilidade caracterizada segundo um traço social agrupa 1.036 pessoas, ou seja, 91\% dos vulneráveis. Trata-se de uma condição que evolui no tempo: geralmente conseqüência da guerra, ela pode desaparecer com a organização social da vida no campo. U ma mulher viúva encontra um novo cônjuge no campo, onde este igualmente chegou sozinho; uma criança sozinha encontra uma família de acol hida etc. M as uma condição considerada vulnerável no campo pode também não ser um efeito direto da guerra (deficiência física, progenitor sozinho etc.), mas apenas ter tornado mais difícil o efeito social daquela. A vulnerabilidade é ainda um estatuto negociável, como o mostra o movimento de mulheres refugiadas de Boreah. Vimos que "mulher sozinha" e "progenitor sozinho", invocados pelas mulheres, formam as categorias mais numerosas entre aquelas consideradas vulneráveis pelo ACN UR. Elas abrem uma brecha para a ação reivindicatória dos refugiados em nome de uma "vulnerabilidade" ambígua do ponto de vista do ACN U R e das organizações humanitárias: genérica para a legitimação externa da ação humanitária, excludente para a gestão interna.

\section{Campos de Dadaab (Quênia)}

A réplica simétrica da intervenção militar que se prevalece de uma finalidade humanitária como modo de legitimação - e da qual sepode dizer queé o cúmulo da submissão, pelo Império, desua "mão esquerda" - éo boicoteda ração alimentar ou seu desvio pelos refugiados, como recusa do estatuto de vítima que essemodo de legitimação implica. A ração do Programa Alimentar M undial da O N U eleva-sea um máximo de 2 mil quilocaloriaspor dia, 0 que representa, na verdade, uma quantidade de simples sobrevivência. $M$ as, 
16. Para uma descrição detalhada sobreatransformação dos campos em novos contextos sociais, ver Agier (2002b).

17. Rádio internacional da cadeia britânica, que difunde na região dois jornais por dia em língua somali. além de essa quantidade raramente ser atingida, sobretudo nos campos africanosnosúltimos anos, sua própria composição produz degenerescências ou mesmo "catástrofes nutricionais inesperadas" (Q ueinnec e Rigal, 1995, p. 116). Algumas avitaminoses - entre outras, o escorbuto, a pelagra ou o beribéri - provêm da falta de vitaminas contidas em frutas, legumes e laticínios, ausentes da ração, esão tanto maisgraves quanto maislongafor a presença de refugiados ou deslocados nos campos. H á dois tipos de ações de sobrevivência contra a composição inadequada ou simplesmentea má qualidadedas rações. U ma, coletiva, consisteem boicotar a distribuição. A outra, mais difundida, éaparentemente individual, mas tem efeitos importantes do ponto de vista da ressocial ização dos refugiados: consisteem reven der uma parte da ração recebida para poder comprar nos pequenos mercados dos campos os alimentos vitaminados quefaltam (legumes, frutas, peixe, carne). Com osmercados, os camposseanimam, o dinheiro circula, trocas se efetuam, um pouco de "cidade" écriada ${ }^{16} . .$.

Protestos desse tipo surgiram nos campos de refugiados de $D$ adaab, no nordeste do Q uênia, um sítio que reúne ao todo 125 mil refugiados. Em junho de 2000, houve um boicote contra a má qual idade de certos produtos da ração alimentar, durante o qual um grupo de refugiados forneceu informações à BBC World ${ }^{17}$, para que sua ação fosse conhecida em toda a África oriental. D o mesmo modo, alguns meses antes, uma greve de vários dias foi organizada por refugiados empregados como trabal hadores voluntários, para obter de algumas $\mathrm{ON}$ Gs a revalorização de sua remuneração mensal - remuneração oficiosa na medida em que, no direito queniano, os refugiados não podem trabalhar nem receber um salário.

\section{A política da vida que resiste}

Acolhidos em nome dos direitos humanos por $\mathrm{ON}$ G s nacionais ou internacionais e organizações da $\mathrm{ONU}$, é como puras vítimas que os refugiados são tratados, como se devessem sua sobrevivência apenas ao fato de não mais "estarem no mundo".

Assim definida, a situação dos refugiados rompe a continuidade entre o homem eo cidadão. É também o queassinala basicamente Giorgio Agamben (1997, pp. 137-146), para quem o refugiado encarna "a fase extrema da separação entre os direitos do homem e os direitos do cidadão" (I dem, p. 144). Essa hipótese, no entanto, só é operatória se estimula, em sentido contrário, a pesquisa empírica sobre a emergência da política em seus espa- 
ços maisimprováveis, em particular nos campos de refugiados. A proposição de Agamben não pode ser considerada uma constatação da realidade dos espaços humanitários. D e fato, o espaço vivido dos refugiados éa priori um não-lugar e um vazio no plano sociológico e político, mas esteé preenchido de relações - as mesmas que são criadas pela intervenção humanitária e pela formação dos espaços-tempos dos refugiados. Em outras palavras, se quisermos ver com justiça toda a complexidade da situação dos refugiados, não podemos associar exclusivamentea questão dos direitos políticos à da inscrição nacional. N estes tempos de mundialização, outros espaços podem ser os lugares da existência política. A problemática dos refugiados, desse ponto de vista, é exemplar.

Agir, tomar a palavra nos lugares de seu exílio, é, para os refugiados, recusar a vulnerabilidade como tratamento da pura vítima sem nome, ao mesmo tempo em que se inscreve no espaço que ela funda mais nitidamente, o dos campos. N asce aí a única revolta possível, a que encarna uma política da vida que resiste.

\section{Campo de Tobanda (Serra Leoa)}

O s campos de refugiados constituem-se como meios sociais e políticos paral elamenteà sua construção material. Esse engendramento só se percebe em geral a posteriori, quando os campos se tornaram, com o tempo, espé cies de projetos de cidades largados ao abandono; de uma maneira mais geral, espaços de identificação para aquel as e aqueles que vivem lá há vários anos ou décadas, ou que lá nasceram, se casaram, enterraram seus mortos ${ }^{18}$. N esse embrião de vida política, líderes emergem e se tornam, oficialmente ou não, os porta-vozes dos refugiados, mesmo que não desejem ser reconhecidos a priori por essa identidade coletiva imposta. São eles que, no fim de contas, defendem o ponto de vista dos "vulneráveis", seja qual for sua condição - e mesmo se a condição deles, relativamente melhor que a da maioria dos refugiados, Ihes permite precisamente exercer essa liderança. É nesse momento, na tomada da palavra "em nome dos refugiados" - todos eles considerados "vulneráveis" -, que a política se introduz no campo, e com ela um pouco de cidadania. É o que ilustram as estratégias de alguns refugiados verificadas no campo de Tobanda, em Serra Leoa.

Em novembro de 2003, o campo contava com 7.500 refugiados liberianos. Aberto seis meses antes, éo mais recente dos oito campos inaugurados desde2001 na região deBô, no sudestedo país, queabrigam no total 55 mil
18. A propósito dos campos-cidades, ver Agier (2002b, pp. 75125); sobre os sítios humanitários como espaços de identificação, ver Agier (2003). 
19. A administração do campo está a cargo do ramoserraleonêsdeuma O N G confessional internacional, à qual 0 AC N U R delegaagestão do campo, em colaboração com o N ACSA (organismo serra-leonês de assistênciasocial). Como acontece com freqüência, aadministração conta entreseu pessoal com al guns liberianos (refugiadosdelongadata, mas queadquiriramo estatuto demigrantes com direito detrabalhar), além dosquadros nacionais.

20. Presidente da Libé ria desde 1997, apóster aterrorizado o país durante sete anos, foi derrubado em agosto de 2003 pelas forças rebeldesapoiadaspelacomunidade internacional.

21. O s casos de lideranças femininas, como o mencionado (campo de Boreah, Guiné Florestal), são raros, mas não inexistentes.

22. A administração do ACN UR chama "comunidade" cadasetor do campo queagrupa vinte compartimentos construídosem voltadeuma tenda coletiva, e onde são reunidos, por ordem de chegada, os recémchegados. $\mathrm{H}$ áassimuma refugiados liberianos. H áaí conflitos para decidir sobre a representação oficial dos refugiados na administração do campo ${ }^{19}$ : a eleição do chairman, 0 representante e porta-voz dos refugiados, foi várias vezes contestada nos seis meses de existência do campo. Eleição indireta da primeira vez, com pouco mais de uma centena de eleitores entre os primeiros 1.500 chefes de tenda a chegar ao campo; eleição direta na segunda vez, quando o campo atingia a população de cerca de 5 mil pessoas, todos os adultos depositando na urna um voto, durante a qual, dizem, certas fraudesteriam ocorrido. Essa elei ção foi anulada pelosadministradores do campo não por causa das fraudes, mas porque o chairman eleito ameaçava a tranqüilidade do campo: segundo alguns, ele era suspeito de querer provocar riots (motins); segundo outros, de atiçar "disputas tribais". A administração o demitiu e nomeou em seu lugar um acting chairman, adiando sinedieuma nova eleição. Com cerca de trinta anos de idade, esse acting chairman tem pouca formação escolar (ao contrário dos habituais jovens leaders), nenhuma experiência de representação e uma atitudegeralmenteagressiva eparcial em relação aos refugiados. D efensor virulento de Charles Taylor ${ }^{20}$, não conta com nenhum apoio entre os refugiados, mas para osadministradores do campo (para os quaisjátrabal hava de vez em quando) pareceu suficientemente colaborador para assisti-los em seu controle. Em realidade, sob a pressão dos leaders refugiados, 0 acting chairman viu-se progressivamente substituído por outros representantes em suas funções de porta-voz dos refugiados. 0 que não incitou os administradores, porém, a organizar novas eleições, pois al egavam (quando a questão Ihes era colocada) que "o campo não tem necessidade de democracia" para ter um funcionamento satisfatório.

Uns vinte refugiados, pelo menos, exercem influências, que eles tentam "fixar" no sistema social e político do campo em via de formação. Essas influências fundam-se, de uma maneira geral, em funções masculinas de relativo prestígio ou poder já adqui rido o ${ }^{21}$; pastores epregadores de igrejas cristãs (pentecostais, em particular, cujo crescimento é rápido no campo); líderes de "comunidades" do campo22; empregados das O N G s que intervêm no campo. H á um princípio cumulativo dos poderes- econômicos, religiosos, políticos - e, finalmente, os que estão em posição de falar "em nome dos refugiados" são os menos vulneráveis entre eles. 0 que não quer dizer, no entanto, queo que eles dizem não éverdade. É o princípio mesmo da representação, do falar "em nomede..." numa cena específica detomadas depalavra e, nesse quadro, a formação de um sujeito político, que estão sendo elaborados aqui. A representação existe, assim, segundo uma modalidade ativa 
desubj etivação, bem distinta da "representação" entendida como representatividadecategorial dos refugiados: os direitos humanos destes são deduzidos automaticamente pelos organismos de gestão da ajuda humanitária, a partir das identidades atribuídas, sejam elas gerais ("refugiados") sejam particulares ("categorias vulneráveis"). Esse direito humano de sobrevivência desaparece a partir do momento em que, localmente, cada governo humanitário é interrompido por decisão das organizações de assistência eda 0 N U . A distinção entreas figuras do refugiado ativo (imprevisto) edo refugiado passivo (previsto, mesmo que seja ocasionalmente criticado) é central. Ela permite ler a transformação da vítima humanitária em sujeito político, no terreno mesmo que produz as identidades não escolhidas, impostas e categoriais, de "refugiado" e de "vulnerável".

Toda tomada de palavra, toda iniciativa, toda expressão política que emerge, o faz em nome do direito à vida, uma vida mantida em espaços de sobrevivência fora da política. N esse sentido, é de fato uma política da vida que se inventa e se exprime nesse momento, como a réplica exatamente simétrica do biopoder que organiza esses espaços excluindo a política. 0 único modelo que podeadvir nosterrenos do humanitário não é, portanto, o do campo "que substitui" a cidade, como sugere Agamben. Com efeito, a fórmula segundo a qual "o campo [de refugiados] éo paradigma mesmo do espaço político no momento em que a política se torna biopolítica" (Agamben, 1997, p. 184) supõe um funcionamento estrutural dos espaços sociais, enão apresenta a questão dos sujeitos e da subjetivação política (cf. Rancière, 2000; Agier, 2002b, p. 123). Ao contrário, quando a política, considerada do ponto de vista da ação e da subjetivação, desdobra-se no campo, este se deffaz em cidade: éo que revelam a ação, visível ou invisível, dos que ali residem, suas respostas ou resistência ao acantonamento, seus expedientes e fraudes, seus protestos e manifestações coletivas.

A identificação faz-se na ação que ressocializa os refugiados; essa proposição não é aplicável àquela que associa a categoria soci odemográfica de "refugiado" a uma identidade, e esta a uma origem - o lugar de onde vem o des-locado e para onde ele deve retornar. $0 \mathrm{~s}$ deslocados e refugiados cessam de sêlo não quando retornam "para suas casas", mas quando lutam como tais por seu corpo, sua saúde, sua socialização: cessam então de ser as vítimas que a cena humanitária implica para se tornarem os sujei tos de uma cena democrática que el es improvisam nos lugares onde estão ${ }^{23}$. N a melhor das hipóteses, portanto, os sítios humanitários só podem ser espaços em tensão. centena de "comunidades" de habitações no campo deTobanda. Os "leaders de comunidade" são em geral refugiados que assumiram a função dechefesdetenda na chegada.

23. A propósito dasdistinções entre cena humanitáriaecenademocrática, ver Rancière (1995). 


\section{Referências Bibliográficas}

ACN UR - Alto Comissariado das N ações Unidas para os Refugiados. (2000), Les réfugiés dans le monde: cinquante ans d'action humanitaire. Paris, UNHCR/ Autrement.

Agamben, Giorgio. (1997), Homo sacer: le pouvoir souverain et la vie nue. Paris, Seuil.

Agier, M ichel. (2002a), "La ville nue: des marges de l'urbain aux terrains de I'humanitaire". Annales de la recherche urbaine, 93.

. (2002b), Au bord du monde, les réfugiés. Paris, Flammarion. . (2003), "Identifications dans I'exil: les réfugiés du camp de M aheba (Zambie)".

Autrepart, 24: 73-89 (Sociétés dans la guerre).

Agier, Michel \& Bouchet-Saulnier, Françoise. (2003), "Espaces humanitaires, espaces d'exception". In: W eIsSm An, F. (org.), A l'ombre des guerres justes: l'ordre international cannibale et l'action humanitaire. Paris, Flammarion, pp. 303-318. Appadural, Arjun. (1996), M odernity at large, cultural dimensions of globalization. M inneapolis, University of M innesota Press.

Bourdieu, Pierre. (1993), "La démission de l'État". In: (dir.), La misère du monde. Paris, Seuil, pp. 219-228.

Bouteillet-Paquet, D aphné. (2002), “Q uelle protection subsidiaire dans I'U nion européenne?". H ommes et M igrations, 1238: 75-87.

Brauman, Rony \& Salignon, Pierre. (2003), "I kak: la posture du missionnaire". In: W eISSM AN, F. (org.), A l'ombre des guerres justes: l'ordre international cannibale et I'action humanitaire. Paris, Flammarion, pp. 275-291.

D Avis, M ike. (1997), City of Q uartz: Los Angeles, capitale du future. 1a edição 1990. Paris, La D écouverte.

D ufour, Jean-Louis. (2001), "L'armée face à la ville". Annales de la recherche urbaine, 91: 35-42.

H ARdT, M ichel \& Negri, Antonio. (2000), Empire. Paris, Exils.

Q UEINNEC, Erwann \& RIGAL, Jean. (1995), “Aide alimentaire et carences vitaminiques dans les camps de réfugiés". In: JeAn, F. (org.), Populations en danger 1995. M SF, La D écouverte, pp. 114-120.

Rancière, Jacques. (1995), La mésentente: politique et philosophie. Paris, Galilée. . (2000), "Biopolitique ou politique?". Multitudes, 1: 88-93.

RıviĖRe, Philippe. (2002), "L'asile aux antipodes”. Le M onde Diplomatique, M anières deVoir, 62. 


\section{Resumo}

Refugiados diante da nova ordem mundial

Em um contexto em que as guerras se transformaram, envolvendo cada vez mais civis e meios urbanos, e no quadro de uma nova tensão nas relações norte-sul (em particular entre a Europa e a África) a respeito das migrações internacionais, a intervenção humanitária muda de sentido e de função. C ada vez mais ela se orienta para o controle e o confinamento dos desenraizados, dos refugiados, dos que reivindicam asilo e de todos os que, em um momento ou outro de sua trajetória, são qualificados de clandestinos. Em sua intervenção, os funcionários da ajuda humanitária lidam com a "vida destituída" dos dependentes de auxílio, tratados como vítimas absolutas e despojados de qualquer inserção social. Entretanto, na clandestinidade ou nos próprios campos, os refugiados tomam a palavra e desenvolvem iniciativas e respostas a seu confinamento, elegendo muitas vezes como alvo as organizações humanitárias governamentais ou da ON U. A linguagem humanitária é, assim, reutilizada ou redirecionada. Palavras-chave: Ajuda humanitária; Refugiados; Ação política.

\section{Abstract}

Refugeesface the new humanitarian order

The meaning and function of humanitarian interventions have changed as an outcome of a new scenario: war in urban spaces with increased involvement of civilians and new tensions between north and south (in particular Europe and Africa) about international migration. M ore and more humanitarian action tries to control and to confine displaced people, refugees, asylum claimers and all that people designated as clandestine. These people are regarded as victim and devoid of any social ties. $\mathrm{H}$ owever, as clandestine or as inhabitants of champs, the refugees work out responses and initiatives to the confinement. The target is often humanitarian organizations supported by $\mathrm{ONU}$ or governments. The humanitarian language is in this way recycled and politicized by its subjects.

Keywords: H umanitarian aid; Refugees; Political action.

M ichel Agier é antropólogo, diretor deestudos daÉ cole des $\mathrm{H}$ autes Études en Sciences Sociales (EH ESS, Paris), diretor de pesquisas no Institut de Recherche pour le D éveloppement (IRD , Paris) e, atualmente, diretor do Centred'ÉtudesAfricaines(CN RS-EH ESS, Pa ris).E-mail: agier@ehe ss.fr. 